\title{
Tulane
}

Tulane Economics Working Paper Series

\section{Estimating Tax Agency Efficiency}

\author{
James Alm \\ Department of Economics \\ Tulane University \\ jalm@tulane.edu
}

\author{
Devil Duncan \\ School of Public and Environmental Affairs \\ Indiana University-Bloomington \\ Institute for the Study of Labor (IZA) \\ duncande@indiana.edu
}

Working Paper 1404

March 2014

\begin{abstract}
Empirical work on a tax agency's production process has been plagued by the absence of comparable tax administrative data across countries and years. Such data are now available from the Organisation of Economic Co-operation and Development. This paper uses these data for the years 2007 to 2011, together with an estimation strategy that utilizes data envelopment analysis and stochastic frontier analysis, to determine the relative efficiency of tax agencies in their use of inputs. Overall, the average efficiency scores indicate that countries should be able to collect their current level of revenues with approximately 10 to 16 percent less inputs.
\end{abstract}

Keywords: tax administration, tax efficiency, data envelopment analysis, stochastic frontier analysis JEL codes: H2, H26, H61, H83 


\title{
Estimating Tax Agency Efficiency
}

\author{
James Alm and Denvil Duncan
}

Empirical work on a tax agency's production process has been plagued by the absence of comparable tax administrative data across countries and years. Such data are now available from the Organisation of Economic Co-operation and Development. This paper uses these data for the years 2007 to 2011, together with an estimation strategy that utilizes data envelopment analysis and stochastic frontier analysis, to determine the relative efficiency of tax agencies in their use of inputs. Overall, the average efficiency scores indicate that countries should be able to collect their current level of revenues with approximately 10 to 16 percent less inputs.

James Alm is professor and chair of the Department of Economics, 208 Tilton Hall, Tulane University, New Orleans, LA 70118 USA; tel. +1-504-862-8344; fax +1-504-865-5869; email jalm@tulane.edu. His teaching and research are in the area of public economics, in such areas as tax compliance, the tax treatment of the family, income reporting, and tax reform.

Denvil Duncan is an assistant professor in the School of Public and Environmental Affairs, Indiana University-Bloomington, 1315 East 10th Street, Bloomington, IN 47405 USA; and Institute for the Study of Labor (IZA), Bonn, Germany; tel. +1 812-855-7493; fax +1 812-8557802; email: duncande@indiana.edu. His research has examined the impact of tax evasion opportunities on labor supply, income inequality, risk exposure, and tax incidence.

We are grateful to David Autor, Leslie Robinson, Justin Ross, and Joel Slemrod for helpful discussions and to Ella Wind for assistance in assembling the data set. 


\section{INTRODUCTION}

Tax administrations exist largely to ensure compliance with the tax laws, and the effectiveness with which tax agencies fulfill their mission has always been a high priority for governments. However, although the administrative dimension of taxation has long been recognized by tax administrators, especially those working on tax policy in developing countries (Goode 1981; Bird and de Jantsche 1993), there has been little systematic analysis of this administrative dimension, at least by economists. The available, but often mainly anecdotal, evidence from government budgetary information clearly indicates that the budget cost of collecting individual income, business income, and sales taxes is generally in excess of 1 percent of the revenues from these taxes, and can sometimes be substantially higher (Sandford 1995). Unfortunately, there is little systematic information on how "efficient" any tax administration may actually be in using administrative "inputs" (e.g., personnel, materials, information, laws, procedures) to generate "outputs" like tax revenues.

Recent world-wide fiscal trends of spiraling government deficits and mounting debt have added considerable pressure to the revenue collections agencies on at least two fronts. There is the obvious pressure to increase tax collections, which under current tax laws can only occur through increased enforcement. Simultaneously, the fiscal strain is forcing cutbacks in resources allocated to the tax agencies, as illustrated in recent suggestions that the budget of the U.S. Internal Revenue Service (IRS) be reduced. Administrative agencies are therefore being asked or forced - to do more, and to do more with fewer resources. These developments also mean that inefficient agencies will need to take steps to increase the efficacy of their tax collection operations if they are to maintain their current budget appropriations. 
Implicit in this shift of policy makers' expectations are the twin notions that the current operations of tax agencies are inefficient and that these inefficiencies can be corrected. Both notions are plausible, but neither is necessarily true. Importantly, neither is very well understood. There have been few attempts to measure the operating efficiency of tax agencies, so it is simply unknown whether they are in fact inefficient. Further, even if the agencies are inefficient, tax administrators have limited control over such variables as a country's tax capacity, its tax laws, and the willingness of taxpayers to participate in the formal versus the informal sector. These variables define an agency's operating "environment", and are largely outside the administrator's control. Of course, the agencies can influence internal agency allocations and processes, and there are also likely to be some other environmental factors that affect tax collections over which tax administrators have some control. To improve revenue performance, policy makers therefore need to focus both on the relative efficiency of tax agencies and also on those factors that affect efficiency over which administrators have some control.

The purpose of this paper is to address these issues. Specifically, we attempt to determine the relative efficiency of tax collection agencies. While public spending efficiency has received a great deal of attention, tax collection efficiency has received considerably less notice, largely because the absence of comparable data across countries on tax administration has made the comparative analysis of tax agencies impossible. ${ }^{1}$ The recent compilation of data by the Organisation of Economic Co-operation and Development (OECD) on administrative performance across countries has now provided this information. There are some limitations of these data, as we discuss later. Even so, these data are the best currently available information on comparative administrative performance, and they are now starting to be used in research that

\footnotetext{
${ }^{1}$ Due to data limitations, most of the existing studies tend to focus on revenue collection agencies within a specific country.
} 
examines tax agencies (Robinson and Slemrod 2012). We use these data, together with a novel three-step estimation strategy, in our empirical analysis of tax agency efficiency.

The three-step method combines data envelopment analysis (DEA) (Charnes, Cooper, and Rhodes 1978) and stochastic frontier analysis (SFA) (Fried et al. 2002; Adam, Delis, and Kammas 2011) to estimate relative efficiency scores, which are comparable across time and space. An input-oriented, variable-return-to-scale DEA is used to estimate relative efficiency scores in the first stage. We use salary and information technology (IT) administrative costs related to tax functions as inputs. As our outputs, we use total tax revenues, and corporate income tax (CIT), personal income tax (PIT), and value-added tax (VAT) revenues separately and in various combinations. The relative efficiency scores from this first stage are then used as left-hand side variables in a second stage SFA to estimate the impact of environmental factors and statistical noise (or "luck") on relative efficiency. The estimated parameters from the second stage are used to make proportional adjustments to the observed inputs, which places all tax agencies on a "level playing field" in terms of environmental factors and statistical noise. Finally, the first stage is repeated using the adjusted, instead of the observed, inputs in the third stage. The relative efficiency scores obtained in the third stage are purged of all environmental factors and statistical noise, thus making cross country comparisons meaningful. Our models are estimated using data from 28 OECD countries for the period 2007 to 2011 . The data are averaged over the five-year period to produce a cross section with 28 observations.

Our preferred third stage results indicate that 13 of the 28 countries are relatively efficient at collecting any of the three types of tax revenues. Overall, the average efficiency scores range from 0.838 to 0.904 across the various tax revenue (or output) measures. These results imply 
that, on average, countries should be able to collect their current level of revenues with approximately 10 to 16 percent less inputs.

Our paper contributes to the literature in three important ways. Of most importance, to our knowledge this is the first known attempt to estimate DEA/SFA relative efficiency scores of tax agencies across countries. Existing papers on the taxation side of the literature focus mainly on tax agencies within a given country (Thanassoulis, Dyson, and Foster 1987; Barros 2007; Katharaki and Tsakas 2010). ${ }^{2}$ While such an intra-national perspective has some advantages, we argue that an international study is especially relevant in today's globalized world. It is not uncommon for policy makers to compare their tax burdens, broadly defined, and other dimensions of their tax systems with that of other countries. The current study adds another dimension to this debate, on the relative efficiency of tax administrations across countries.

Second, our measure of efficiency is also different from other common measures, such as the C-efficiency ratio for the VAT (Aizenman and Jinjarak 2008) or simple tax ratios (e.g., costto-revenue), often used to measure the efficiency with which tax revenues are collected. A major drawback in using these measures is that they fail to account for the fact that tax collection is a production process that uses multiple inputs to produce multiple outputs. Estimating DEA/SFA efficiency scores makes it possible for us to account for these inputs and outputs and also for the environmental factors that affect how the inputs are combined in the production process.

Third, we assemble a data set of efficiency scores that are consistent and comparable across countries. This is especially important in the current economic climate where countries continue to compare themselves on various margins as they formulate fiscal policies aimed at reducing deficits and debt. Our efficiency rankings provide policy makers with a more accurate

\footnotetext{
2 There is an extensive literature using DEA to assess the relative efficiency of public expenditure. See the many references in Balaguer-Coll et al. (2007), Rayp and Sijpe (2007), and Adam, Delis, and Kammas (2011).
} 
picture of where they stand relative to comparable countries. It is also possible to use eventually the relative efficiency scores as left-hand-side variables to explore the determinants of relative efficiency among countries. In doing so, we will be able to identify policies that governments can pursue to improve tax administration efficiency. However, making this next step requires a data set with a longer time dimension than is currently available. We believe this will be possible within a few years as the OECD expands its data set.

In the remainder of the paper we first describe the three-step estimation strategy. We then discuss the data and our results. We conclude in the final section.

\section{EMPIRICAL STRATEGY}

We use a three-step DEA/SFA method to rank countries based on the relative efficiency of their respective tax agencies (Fried et al. 2002). In the first stage we use DEA to measure the relative efficiency of decision making units. This approach is favored because it can deal with production processes that have multiple inputs and outputs, and it imposes no parametric assumptions on the data. For these reasons, DEA has been used in a number of public finance studies to assess the relative efficiency of public spending (Adam, Delis, and Kammas 2011) and taxation (Thanassoulis, Dyson, and Foster 1987; Barros 2007; Katharaki and Tsakas 2010). However, because DEA excludes non-discriminatory variables, a second stage regression analysis is often used to identify key variables that may affect a unit's ability to carry out its mandated function. These variables define the environment within which each unit must operate and are outside of the tax agency's control. The second stage results then allow us to repeat the first stage using the adjusted inputs in a third stage estimation, where the adjustments are 
determined by the second stage estimates. This section provides more details on each step of the estimation strategy.

\section{Step 1: Data Envelopment Analysis}

Data envelopment analysis (DEA) in its current form was first introduced by Charnes, Cooper, and Rhodes (1978) for the explicit purpose of measuring the relative efficiency of decision making units (DMUs) with multiple inputs and outputs. It is a linear programming optimization methodology used to estimate a piece-wise linear production possibility frontier by choosing a weight for each input and output such that the relative efficiency score for each DMU is maximized. The efficiency score for each DMU is then compared to the frontier to determine its relative efficiency. DMUs are relatively efficient if they fall on the frontier and relatively inefficient otherwise. We present here a basic outline of an input oriented DEA model with variable returns to scale. ${ }^{3}$ The input orientation model treats outputs as fixed and targets proportional input adjustments as the path to efficiency. ${ }^{4}$

The input oriented variable returns to scale model is specified as follows:

$$
\begin{aligned}
& \operatorname{Min} \theta_{o}-\mathcal{E}\left(\sum_{r} s_{r}^{+}+\sum_{r} s_{r}^{-}\right) \\
& s t . \\
& \sum_{d} \lambda_{d} x_{d i}+s_{i}^{-}=\theta_{o} x_{o i}, \quad i=1, \ldots, m \\
& \sum_{d} \lambda_{d} y_{d r}-s_{r}^{+}=y_{o r}, \quad \mathrm{r}=1, \ldots, s \\
& \lambda_{d}, s_{i}^{-}, s_{i}^{+} \geq 0, \quad \forall r, i, d \\
& \sum_{d} \lambda_{d}=1,
\end{aligned}
$$

\footnotetext{
${ }^{3}$ DEA has evolved significantly since its inception in 1978. See Cook and Seiford (2009) for a recent review of various extensions to the original model.

${ }^{4}$ We acknowledge that the way in which inputs are used is just as important as the level of inputs used. For example, the distribution of workers across various tax collection tasks will affect the amount of revenues collected. Therefore, two tax agencies with similar staff levels may collect different levels of revenues because of how those workers are used. Unfortunately, we do not have enough information to address this possibility.
} 
where $x_{d i}$ and $y_{d r}$ are input $i$ and output $r$, respectively, in DMU $d$, and $s_{i}$ and $s_{r}$ are input and output slacks, respectively. There are, of course, other techniques that can be used to estimate relative efficiency scores. For example, stochastic frontier analysis (SFA) is also able to estimate efficiency scores using a parametric framework that accounts for environmental factors and statistical noise. However, the parametric nature of SFA makes it susceptible to specification errors that are exacerbated in small samples (Rayp and Sijpe 2007). Because DEA is nonparametric, it is well suited for estimating efficiency scores in small samples such as ours.

One of the unique features of DEA is that it allows for multiple inputs and outputs. However, including too many inputs and outputs in the model reduces its discriminatory power (Thanassoulis, Dyson, and Foster 1987). As a rule of thumb, the number of DMUs should be greater than three times the sum of inputs and outputs. Because our sample is relatively small, we are forced to choose the smallest number of inputs (two) and outputs (at least three) that best captures the operating conditions of each tax agency. Although this list is by no means exhaustive, we feel it is a reasonable compromise given the data limitations. ${ }^{5}$

As we discuss later, our two inputs are salary costs and information technology (IT) costs for tax functions, as shares of total administrative costs (or, in some alternative estimates, relative to the total labor force in the country). These two cost categories account for more than 80 percent of total administrative costs in 73 percent of the countries in our sample. They are also cost categories that are measured consistently across the countries in the OECD data.

The output produced by tax agencies can be measured in several ways. One could examine the rate at which contested cases are resolved (Barros 2007), the number of actions that are taken against delinquent accounts (Katharaki and Tsakas 2010), or the number of returns that

${ }^{5}$ Other methodologies would allow us to include additional inputs and outputs, such as stochastic frontier analysis (SFA). However, the SFA approach is sensitive to model specification especially in small sample sizes such as ours. Because DEA is a nonparametric technique, it does a better job in small samples. 
are audited (Moesen and Persoon 2002). An ideal analysis would also distinguish between revenues collected via voluntary payments and revenues collected through explicit enforcement activities. Unfortunately, we do not have enough information on the sources of revenues to account for this distinction. As a result, our output measures focus exclusively on tax revenues, measured separately as PIT revenue, CIT revenue, and VAT revenue, as total revenues, and as various combinations of these revenues. We take these as the most appropriate measures of output since the core objective of tax agencies is to collect revenues. ${ }^{6}$

It should be noted that we have estimated our model with alternative measures of inputs and outputs; for example, we use total staff as a share of total labor force and administrative costs as a share of the total labor force in some of our robustness checks. We have also estimated our model with two inputs and a single output (e.g., total revenues); all results are available upon request. Although we are unable to specify more disaggregated measures of inputs and outputs, our analysis still allows us to comment on how well tax agencies use the total amount of inputs to generate the total amount of revenues. We believe answering this question is an important first step in identifying the efficiency of tax agencies.

\section{Step 2: Stochastic Frontier Analysis (SFA)}

The DEA procedure estimates relative efficiency scores that do not account for nondiscriminatory factors, mainly factors that define the operating "environment" of tax agencies and that are largely outside of their direct control. This makes the use of DEA score comparisons across countries misleading since a country with, say, a favorable environment is more likely to

\footnotetext{
${ }^{6}$ An alternative approach would be to rely on revenue collected as a share of total revenue outstanding, something akin to a tax gap measure. This measure would give us a better idea of "return on investment": given the amount of money spent on administering the tax, how close is each agency to collecting its outstanding revenue? However, we are not able to determine revenue outstanding for each country because these data simply do not exist on a large scale. For example, we know of only two recent tax gap estimates for the United States (2001 and 2006). Most of the countries in our sample do not have estimates of their tax gap. Therefore, it is not possible to use this measure.
} 
outperform a country with a less favorable environment, all else equal. We address this issue by using the first stage results to estimate a stochastic frontier analysis (SFA) model that allows us to adjust for factors outside the control of the DMUs (Adam, Delis, and Kammas 2011; Fried et al. 2002).

The second stage SFA model has the form:

$$
\theta_{d j}=f\left(z_{d} ; \beta\right)+v_{d j}+u_{d j} \quad d=1, \ldots . . D
$$

where $\theta_{d j}$ is the first stage relative efficiency score of DMU $d, f\left(z_{d} ; \beta\right)$ is the stochastic frontier that captures environmental factors, $v_{d j}+u_{d j}$ is the composite error term, $v_{d j}$ captures statistical noise, and $u_{d j}$ captures managerial inefficiency. We assume that the distribution of $v_{d j}$ is $v_{d j} \sim N\left(0, \sigma^{2}\right)$; we make no distributional assumption on $u_{d j}$ although we could assume normality as in Fried et al. (2002). This specification differs from Fried et al. (2002) in that we use the efficiency score as our dependent variable while they used the input slacks. Because we use the efficiency score, we estimate a single regression in the spirit of Adam, Delis, and Kammas (2011). ${ }^{7}$

The $z_{d}$ vector includes three measures meant to capture the tax capacity of the tax units. Since tax capacity defines the maximum amount of revenues that a tax unit can expect to collect independent of the amount of inputs used, tax capacity is outside the tax unit's control. Consequently, it is important that we control for these tax capacity differences in order to determine an accurate country ranking on the basis of collection efficiency. We use the share of services in gross domestic product (GDP), the share of agriculture in GDP, and openness (measured as exports divided by the sum of exports and imports) to control for tax capacity (Bahl

\footnotetext{
${ }^{7}$ It is also possible to include a time dimension, as in Adam, Delis, and Kammas (2011). However, we do not have sufficient within variation in our data to pursue this panel regression approach.
} 
1971; Bird, Martinez-Vazquez, and Torgler 2008). We also include tax rates in the second stage to account for the fact that countries with higher tax rates will collect more revenues conditional on the tax capacity. ${ }^{8}$

The estimated parameters from the SFA are then used to adjust the first stage inputs for environmental factors $z_{d} \hat{\beta}$ and statistical noise $v_{d j}$. This adjustment increases the inputs of each DMU proportional to their environment (e.g., "favorability") and statistical noise (e.g., "luck"). DMUs operating in favorable environments with better luck receive a greater penalty via an increase in inputs.

The adjustment is made as follows:

$$
x_{d j}^{a}=x_{d j}+\left[\max _{d}\left\{z_{d} \hat{\beta}\right\}-z_{d} \hat{\beta}\right]+\left[\max _{d}\left\{\hat{v}_{d}\right\}-\hat{v}_{d}\right]
$$

where $x_{d j}^{a}$ and $x_{d j}$ are adjusted and observed inputs, respectively. The second term on the right puts all DMUs in the same (least favorable) operating environment, and the third term places all DMUs in the same state of nature (unluckiest). ${ }^{9}$ We follow Fried et al. (2002), and identify $\hat{v}_{d}$ using:

$$
\hat{E}\left[v_{d} \mid v_{d}+u_{d}\right]=\theta_{d}-z_{d} \hat{\beta}-\hat{E}\left[u_{d j} \mid v_{d}+u_{d}\right]
$$

\section{Step 3: Adjusted DEA}

In the third stage, the adjusted inputs from step 2 are used to re-estimate the first stage DEA model. The relative efficiency scores obtained in this stage reflect pure managerial efficiency, which is comparable across countries. This comparison is possible because the inputs have been adjusted for both environmental factors and statistical noise. One of the key

\footnotetext{
${ }^{8}$ The appropriate measure of the tax rate depends on the output for which the second stage is being implemented. We use the top statutory PIT rate when output is measured by either the personal income tax revenues or total tax revenues; the top statutory CIT rate is used for CIT revenues; and the standard VAT rate is used for VAT revenues and general tax on goods revenue.

${ }^{9}$ As in Fried et al. (2002), these adjustments are based on a Tobit model whenever the SFA specification is rejected.
} 
assumptions here is that the model is not misspecified. If this assumption fails, then the composite error term will include the effects of the misspecification, which then complicates the interpretation of the error term as white noise and managerial inefficiency. We address this potential concern by including variables that are common in the tax effort/tax capacity literature (Bahl 1971; Bird, Martinez-Vazquez, and Torgler 2008).

\section{DATA}

The three-step method requires three sets of variables: inputs, outputs, and environmental factors. Most of these data are extracted from Tax Administration in OECD and Selected NonOECD Countries: Comparative Information Series, published in 2008, 2010, and 2013, which reports data for years 2007, 2009, and 2011, respectively. ${ }^{10}$ The 2013 report also reports data on some variables for the period 2005 to 2011 . This publication provides information on inputs, outputs, and environmental factors that affect tax administration in thirty four OECD and fifteen selected non-OECD countries. The data are collected from a survey of revenue bodies in the respective countries, and promise to be a fruitful source for data on tax administration, as already demonstrated by Robinson and Slemrod (2012) in their analysis of the many dimensions of tax systems.

Although we have data for several years, we do not exploit this time dimension in our estimation. Instead, we average our measures of inputs and outputs over the period 2007-2011, and then we estimate the models on a cross section of 28 OECD countries. We take this approach because it allows us to address some of the inconsistencies across years and countries. For example, information technology expenditures tend to be lumpy. Because these higher than

\footnotetext{
${ }^{10}$ Note that the name of the OECD publication changed in the most recent year, and is now called Tax Administration 2013: Comparative Information on OECD and Other Advanced and Emerging Economies.
} 
normal expenditures affect revenue collections in more than one year, it would be incorrect to simply use this variable as an input only in the year of the expenditure.

The data collected from the OECD tax administration publication are supplemented by data from two other sources in an effort to maximize the number of observations. We extract central government tax revenue data from OECDStatExtracts and the International Government Financial Statistics (GFS). The GFS data are used to fill in observations not present in the OECDStatExtracts. The combination of data sources produces 28 observations for the PIT and CIT, and total tax revenue, and 27 for the VAT. The countries included in the analysis are: Australia, Austria, Belgium, Canada, Chile, Czech Republic, Denmark, Estonia, Finland, France, Germany, Hungary, Iceland, Ireland, Italy, Japan, South Korea, Luxembourg, Mexico, Netherlands, Norway, Poland, Portugal, Slovenia, Spain, Turkey, United Kingdom, and United States. $^{11}$

All monetary values are expressed in millions of U.S. dollars using exchange rate data from the World Penn Table (PWT7.0). See Table 1 for summary statistics.

A detailed examination of these data indicates that tax rates vary significantly across countries in our sample. The top CIT rate ranges from a low of 8.5 percent (Switzerland) to a high of 35 percent (United States), with a mean of 22.9 percent and a standard deviation of 7.4 percent. Similarly high levels of variation are observed for the top statutory PIT rate (mean of 33 percent and standard deviation of 11.7 percent) and the standard VAT rate (mean of 18 percent and standard deviation of 5.3 percent). This variation in tax rates implies that two countries with similar tax capacity could collect very different levels of tax revenues. We control for this possibility by including tax rates in the second stage of the analysis.

\footnotetext{
${ }^{11}$ Note that the United States is not included in the VAT specifications because the U.S. does not impose a VAT. We also exclude Israel, New Zealand, Sweden, Switzerland and Greece due to missing data, and the Slovak Republic due to outliers.
} 
With some exceptions, the countries in our sample are very similar with respect to the types of taxes used to generate revenue. In particular, corporate income, personal income, and sales are the dominant tax bases among all countries in the sample. These three tax bases in total account for 72 percent to 99 percent of tax revenues, with an average of 91 percent and a median of 94 percent in 2011. Only three countries generate less than 82 percent of tax revenue from these three sources: Estonia (72 percent), Norway (73 percent), and Iceland (76 percent). ${ }^{12}$ However, there is variation in the importance of each tax. For example, the relative importance of the general tax on goods is inversely related to the importance of the personal income tax. Also, the United State does not have a general sales tax, and is instead highly dependent on the PIT. As indicated earlier, we attempt to address this variation in dependence on the various tax bases by estimating the DEA model separately on total tax revenue, PIT, CIT, and VAT revenues and various combinations of these.

Another feature of a country's tax system that likely affects tax collection efficiency is the level of complexity, especially complexity associated with the definition of tax bases. Unfortunately, we are not able to control for differences in the breadth of the tax base due to lack of data. For example, we do not have data on exemptions, deductions, exclusions, credits, and other legal loopholes that can be used to reduce the size of the tax base. We also do not have data on compliance rates. The OECD tax administration report includes information on the use of tax identifiers in the collection process. However, there is very little variation in this feature; for example, only 3 of the countries in our sample do not use personal identifiers for tax collection. Similarly, the use of third-party reporting and or withholding is universal for wage income and almost universal for interest and dividend income.

\footnotetext{
12 The other major revenue source for these three countries is social security contributions, which are 28 percent, 25 percent, and 16 percent for Estonia, Norway and Iceland, respectively.
} 


\section{RESULTS}

\section{Summary Results from First and Second Stages}

While the first stage efficiency scores may be used to rank countries according to their efficiency in collecting tax revenues, such rankings are not particularly meaningful because the operating "environment" of tax agencies varies across countries. Since these environmental factors are often non-discriminatory, the efficiency scores obtained in the first stage are not comparable for the purposes of ranking countries. To make such cross-country comparisons, we rely on the third stage results, which together produce a meaningful ranking of countries by their relative efficiency. We focus our discussion on these third stage results. ${ }^{13}$

Note that the results of the SFA procedure in stage 2 find very little evidence of managerial inefficiency after controlling for environmental factors and noise; that is, correcting for environmental factors and noise (second stage) has no noticeable effect on the resulting third stage average efficiency scores or the countries that are relatively efficient, so that the SFA specification is rejected for each model. As such, the stage 2 adjustment is done using a Tobit model. A similar approach is used by Fried et al. (2002) when the SFA model is rejected.

\section{Relative Efficiency Rankings from Third Stage Results}

The results from the third stage are reported in Table 2. Table A1 in the Appendix lists all efficiency scores and the full rankings of all OECD countries for stage 3.

The results in Table 2 show that the overall performance is high with an average relative efficiency score that ranges from 0.838 when CIT revenue is the only output measure to 0.904 when the model combines PIT, CIT, and VAT as outputs. These results indicate that an average tax unit could generate similar levels of revenue with 10 to 16 percent less inputs. Additionally,

\footnotetext{
${ }^{13}$ All first and second stage results are available upon request.
} 
of the 28 countries in our sample, 13 are relatively efficient in collecting any of the main tax categories: Australia, Belgium, Chile, Denmark, Hungary, Iceland, Italy, Luxembourg, Norway, Poland, Portugal, Slovenia, and the United Kingdom. Overall, the general finding of high relative efficiency for government revenue collection is in stark contrast to Adam, Delis, and Kammas (2011) who use a similar methodology to examine the efficiency of government expenditures for OECD countries alone and who find relatively low efficiency scores for economic affairs and general public services spending accounts.

Overall, the country rankings produced by the third stage are very consistent across output measures. In particular, the countries in the top 10 remain mostly the same regardless of the specified revenue output.

\section{Additional Specifications}

Including OECD and Non-OECD Countries. One of the features of DEA is that its ability to identify relatively efficient decision making units increases as the sample size increases relative to the number of inputs and outputs. We take advantage of this feature by re-estimating the models with a sample that includes both OECD and Non-OECD countries, rather than with just OECD countries as in Table $2 .{ }^{14}$ The results in Table 3 show that the overall average efficiency scores are modestly lower, and range from 0.816 when the CIT is used as output to 0.856 when the PIT, CIT, and VAT are combined. Only 9 of the 38 countries are relatively efficient in any of the models we estimate; 6 of these are OECD countries that were also found to be relatively efficient in the OECD only sample. Although we recognize that comparing OECD and Non-OECD countries can lead to misleading results if appropriate adjustments are not made,

\footnotetext{
${ }^{14}$ The Non-OECD countries are Bulgaria, Cyprus, India, Latvia, Lithuania, Malta, Romania, Russia, South Africa, and Singapore. Table A2 in the Appendix lists all efficiency scores and the full rankings of all countries for stage 3, for both OECD and Non-OECD countries. Note that not every Non-OECD country is included in each model, due to missing observations.
} 
we believe that our normalizations of outputs and inputs (along with the controls in the second stage) address this concern. Nonetheless, as discussed earlier, we are not able to address every possible difference between OECD and Non-OECD countries. We are therefore somewhat cautious when interpreting these results.

Using Alternative Inputs. Although we are able to check our results by varying the measures of output, a similar exercise for inputs is complicated by missing data. Ideally, we would like to use information on technology costs, salary and wages, and other tax-related overhead costs as separate inputs. It would also be desirable to control for other features such as whether a large taxpayer unit exists. Most of these variables are either completely missing from the dataset or only partially available for some of the countries. In this subsection we extend the analysis by using alternative measures of inputs: Salary Costs and IT Costs, now measured relative to the total labor force in each country. Except for this change in inputs, we follow the same methods described previously. Because we only have labor force data in 2007, 2009, and 2011, we estimate the three stage DEA model separately for each of these years. We also estimate the model for the OECD sample and the full sample (OECD and Non-OECD) separately. These results are presented in Tables 4 and 5.

Compared to our baseline estimates in Table 2, the results in Table 4 show that these alternative measures of inputs produce average efficiency scores that are lower in both samples. There is no clear trend in the magnitude of the estimates across years. Note, however, that these results do not allow us to say whether countries are becoming more or less efficient. Drawing this conclusion would require us to hold the sample size fixed, which we are unable to do because of data restrictions (e.g., the sample is smaller in 2007). ${ }^{15}$

\footnotetext{
15 These full results are not presented here, but are available upon request.
} 
These results are used in Table 5 to determine which countries are efficient in collecting any of the measures of taxes in the third stage estimations. Table 5 indicates that all of the countries that were identified as being relatively efficient in Tables 3 and 4 continue to be relatively efficient when the new vector of inputs is used. These results suggest that, while the relative efficiency scores are not directly comparable, the general pattern of our findings is consistent across specifications.

\section{SOME POLICY IMPLICATIONS}

There are various policy implications that follow from these rankings. An especially important implication is that countries that are inefficient can improve their fiscal position by using inputs more efficiently. This section examines this policy implication; we use the estimates from the OECD sample discussed earlier for illustrative purposes.

Looking at the average efficiency scores across the various output measures, we find that in order to achieve efficiency the average country would have to cut its inputs by 10 to 16 percent (depending on the specified output) with a range of 0 percent for efficient countries up to 34 percent for the least efficient country. For example, consider the model with total revenue as the output measure in Table 2 . The average country in this model has a relative efficiency score in the third stage of 0.85 , which implies efficiency can be achieved by reducing both inputs by 15 percent (Glass et al., 2006). Since the average salary cost to total administrative cost in the sample is 72.25 (with standard deviation of 8.97 ), the average country would have to reduce its salary cost to total administrative cost by $1.2(=(0.15 * 72.25) / 8.97)$ standard deviations from the 
mean in order to achieve this gain. ${ }^{16}$ This translates into actual cost savings of approximately US $\$ 267$ million (=0.15*US $\$ 1.78$ billion), where US $\$ 1.78$ billion is the 5-year average expenditure on salary administrative costs among OECD countries. A similar calculation indicates that the average country would need to cut its IT cost to total administrative cost by 0.24 of one standard deviation from the sample mean of 10.93 , or US $\$ 42$ million ( $=0.15 *$ US $\$ 280$ million), where US \$280 million is the 5-year average expenditure on IT administrative costs among OECD countries.

While our results indicate that many countries do not need additional resources devoted to tax administration, these calculations are mainly suggestive and must be interpreted with some caution. Recall that we are forced to use just two broad measures of inputs to characterize the collection efforts of each country, and this aggregation of inputs undoubtedly misses important features of the tax collection process. For example, some countries have taxpayer units that focus exclusively on large taxpayers. One might expect that, for a given level of input, countries with such units are able to collect relatively higher revenues than countries that do not have them. ${ }^{17}$ Also, changing the mix of inputs changes the underlying input ratios used to make the calculations, which may in turn affect the actual revenue impact. Even so, these calculations are consistent with a potentially large revenue impact from improving tax agency efficiency.

\footnotetext{
${ }^{16}$ More precisely, a country that has a mean labor cost share of 72.25 would have to reduce its labor cost share by $10.84(=0.15 * 72.25)$, which is $1.2(=10.84 / 8.97)$ times the standard deviation of labor cost share in the sample.

${ }^{17}$ Ideally, we would include these features of the tax agencies in the first stage since it is reasonable to assume the tax administrators have control over the existence of such units. However, we are unable to include these features because we do not have such data for many countries in our sample.
} 


\section{CONCLUSIONS}

We use a three-step estimation procedure and data from a recent OECD publication on international tax administration to estimate tax revenue collection efficiency scores for a set of OECD and selected Non-OECD countries. Our estimation is done separately for total tax revenue, PIT, CIT, and VAT revenue, and jointly for all three taxes (PIT, CIT, and VAT) and various combinations of these taxes. Our estimation procedure levels the playing field for all countries in our sample, thus making it possible for us to rank countries according to the relative efficiency with which they collect tax revenues.

Our findings suggest that the average performance of OECD countries in collecting tax revenues is high, but this performance is not as impressive in a full sample that includes both OECD and Non-OECD countries. Although the estimated relative efficiency scores are sensitive to the inputs, outputs, and sample used, we find that the relative performance of countries is quite robust to various specifications.

Overall, we view these results as the first step at exploring important but largely unexamined issues on how countries can more effectively utilize tax administration resources. In particular, what role does an efficient - or an inefficient - tax administration play in revenue mobilization? Additionally, the relative efficiency scores can be used as left-hand-side variables to explore the determinant of relative efficiency among countries. In doing so, we will be able to identify policies that governments can pursue to improve tax administration efficiency. However, making this next step requires a data set with a longer time dimension than is currently available. We believe this will soon be possible as the OECD continues to expand the data set. 


\section{REFERENCES}

Adam, Antonis, Manthos Delis, and Pantelis Kammas. 2011. "Public Sector Efficiency: Leveling the Playing Field between OECD Countries." Public Choice, 146 (1): 163-183. Aizenman, Joshua and Yothin Jinjarak. 2008. "The Collection Efficiency of the Value Added Tax: Theory and International Evidence." Journal of International Trade and Economic Development, 17 (3): 391-410.

Bahl, Roy W., Jr. 1971. "A Regression Approach to Tax Effort and Tax Ratio Analysis." IMF Staff Papers, 18 (3): 570-612.

Balaguer-Coll, Maria Teresa, Diego Prior, and Emili Tortosa-Ausina. 2007. "On the Determinants of Local Government Performance: A Two-stage Nonparametric Approach.” European Economic Review, 51 (2): 425-451.

Barros, Carlos Pestana. 2007. "Technical and Allocative Efficiency of Tax Offices: A Case Study." International Journal of Public Sector Performance Management, 1 (1): 41-61.

Bird, Richard, Jorge Martinez-Vazquez, and Benno Torgler. 2008. "Tax Effort in Developing Countries and High Income Countries: The Impact of Corruption, Voice, and Accountability." Economic Analysis and Policy, 38 (1): 55-71.

Bird, Richard and Milka Casanegra de Jantsche (eds.). 1993. Improving Tax Administration in Developing Countries. Washington D.C.: International Monetary Fund.

Charnes, Abraham, William Cooper, and Edwardo Rhodes. 1978. "Measuring the Efficiency of Decision Making Units." European Journal of Operational Research, 2 (6): 429-444.

Cook, Wade and Larry Seiford. 2009. "Data Envelopment Analysis (DEA) - Thirty Years on." European Journal of Operational Research, 192 (1): 1-17.

Fried, Harold, Knox Lovell, Shelton Schmidt, and Suthathip Yaisawarng. 2002. "Accounting for Environmental Effects and Statistical Noise in Data Envelopment Analysis." Journal of Productivity Analysis, 17 (1): 157-174.

Glass, J. Colin, Gillian McCallion, Donal G. McKillop, and Karl Stringer. 2006. “A 'Technically Level Playing-field' Profit Efficiency Analysis of Enforced Competition between Publicly Funded Institutions." European Economic Review, 50 (6): 1604-1626.

Goode, Richard. 1981. "Some Economic Aspects of Tax Administration." IMF Staff Papers, 28 (3): 249-274.

Katharaki, Maria and Marios Tsakas. 2010. "Assessing the Efficiency and Managing the Performance of Greek Tax Offices." Journal of Advances in Management Research, 7 (1): 587-514.

Moesen, Wim and Annick Persoon. 2002. "Measuring and Explaining the Productive Efficiency of Tax Offices: A Non-parametric Best Practice Frontier Approach." Review of Business and Economics, 10 (3): 399-416.

OECD. 2009. Tax Administration in OECD and Selected Non-OECD Countries: Comparative Information Series (2008). Paris, France: OECD Publishing.

OECD. 2011. Tax Administration in OECD and Selected Non-OECD Countries: Comparative Information Series (2010). Paris, France: OECD Publishing.

OECD. 2013. Tax Administration 2013: Comparative Information on OECD and Other Advanced and Emerging Economies. Paris, France: OECD Publishing, available online at http://dx.doi.org/10.1787/9789264200814-en.

Rayp, Glenn and Nicolas Van De Sijpe. 2007. "Measuring and Explaining Government Efficiency in Developing Countries." Journal of Development Studies, 43 (2): 360-381. 
Robinson, Leslie and Joel Slemrod. 2012. "Understanding Multidimensional Tax Systems." International Tax and Public Finance, 19 (2): 237-267.

Sandford, Cedric (ed.). 1995. Tax Compliance Costs: Measurement and Policy, Bath, UK: Fiscal Publications.

Thanassoulis, Emmanuel, Robert Dyson, and John Foster. 1987. "Relative Efficiency Assessments Using Data Envelopment Analysis: An Application to Data on Rates Departments.” The Journal of the Operational Research Society, 38 (5): 397-411. 
Table 1: Summary Statistics

\begin{tabular}{|c|c|c|c|c|c|c|c|c|c|c|}
\hline & Mean & $\begin{array}{l}\text { Standard } \\
\text { Deviation }\end{array}$ & Minimum & Maximum & $\mathbf{N}$ & Mean & $\begin{array}{l}\text { Standard } \\
\text { Deviation }\end{array}$ & Minimum & Maximum & $\mathbf{N}$ \\
\hline Inputs & \multicolumn{5}{|c|}{ OECD sample } & \multicolumn{5}{|c|}{ Full (OECD and Non-OECD) Sample } \\
\hline Salary Cost/Total Administrative Cost & 71.94 & 8.28 & 54.64 & 84.42 & 28 & 71.71 & 10.07 & 46.13 & 95.38 & 39 \\
\hline IT Cost/Total Administrative Cost & 10.72 & 6.73 & 1.84 & 23.35 & 28 & 9.37 & 6.62 & 0.94 & 23.35 & 39 \\
\hline Salary Cost/Labor Force* & 118.65 & 78.59 & 13.94 & 296.91 & 28 & 108.14 & 75.84 & 13.94 & 296.91 & 35 \\
\hline IT Cost/Labor Force* & 19.08 & 18.15 & 0.67 & 63.23 & 27 & 15.20 & 17.46 & 0.38 & 63.23 & 35 \\
\hline \multicolumn{11}{|l|}{ Outputs } \\
\hline Total Tax Revenues (\% GDP) & 20.48 & 6.85 & 9.35 & 36.98 & 28 & 20.62 & 6.64 & 9.35 & 36.98 & 35 \\
\hline PIT Revenues (\% GDP) & 5.92 & 3.36 & 1.25 & 14.33 & 28 & 5.66 & 3.24 & 1.14 & 14.33 & 35 \\
\hline CIT Revenues (\% GDP) & 2.90 & 1.83 & 0.46 & 10.57 & 28 & 3.25 & 2.06 & 0.46 & 10.57 & 35 \\
\hline VAT Revenues (\% GDP) & 6.29 & 2.25 & 1.91 & 10.02 & 27 & 6.68 & 2.30 & 1.91 & 12.24 & 34 \\
\hline \multicolumn{11}{|l|}{ Covariates } \\
\hline Agriculture Value Added (\% GDP) & 2.46 & 1.81 & 0.33 & 9.09 & 28 & 3.42 & 3.05 & 0.33 & 14.70 & 39 \\
\hline Service Value Added (\% GDP) & 69.03 & 6.84 & 57.24 & 85.36 & 28 & 66.12 & 10.25 & 36.10 & 85.36 & 39 \\
\hline Openness & 0.96 & 0.56 & 0.29 & 3.05 & 28 & 0.99 & 0.54 & 0.29 & 3.05 & 39 \\
\hline Standard VAT Rate (\%) & 18.26 & 5.27 & 5.00 & 25.00 & 27 & 17.88 & 5.01 & 5.00 & 25.00 & 37 \\
\hline Top CIT Rate (\%) & 24.47 & 5.76 & 12.50 & 35.00 & 28 & 23.85 & 7.06 & 10.00 & 35.02 & 39 \\
\hline Top PIT Rate (\%) & 36.22 & 9.08 & 18.40 & 52.00 & 28 & 32.62 & 11.26 & 0.00 & 52.00 & 39 \\
\hline
\end{tabular}

Notes: The unit of observation is the country, and, unless otherwise indicated, the value of the variable for each country is averaged over the five-year period 2007 to 2011 . * denotes that reported numbers are for year 2011 only. 
Table 2: Relative Efficiency - Third Stage Estimates with OECD Sample

\begin{tabular}{lcccccc}
\hline Stage & Total Revenue & PIT & CIT & VAT & PIT, CIT, VAT & PIT and CIT \\
\hline First Stage & 0.853 & 0.843 & 0.841 & 0.873 & 0.905 & 0.869 \\
Third Stage & 0.850 & 0.839 & 0.838 & 0.870 & 0.904 & 0.866 \\
$\mathrm{~N}$ & 28 & 28 & 28 & 27 & 27 & 28 \\
\hline \multicolumn{7}{c}{ Efficient Countries } \\
\hline Australia & 0 & 0 & 0 & 0 & 1 & 1 \\
Belgium & 0 & 1 & 0 & 0 & 1 & 1 \\
Chile & 0 & 0 & 1 & 0 & 1 & 1 \\
Denmark & 1 & 1 & 0 & 1 & 1 & 1 \\
Hungary & 0 & 0 & 0 & 1 & 1 & 0 \\
Iceland & 0 & 0 & 0 & 1 & 1 & 0 \\
Italy & 1 & 1 & 1 & 1 & 1 & 1 \\
Luxembourg & 1 & 0 & 0 & 0 & 1 & 1 \\
Norway & 1 & 0 & 1 & 0 & 1 & 0 \\
Poland & 0 & 0 & 0 & 1 & 1 & 1 \\
Portugal & 1 & 1 & 1 & 1 & 1 & 0 \\
Slovenia & 0 & 0 & 0 & 1 & 1 & 0 \\
UK & 1 & 0 & 0 & 0 & 1 & \\
\hline
\end{tabular}

Notes: Relatively efficient countries are indicated by the number 1. The two inputs used in these estimates are 5-year averages of Salary Costs and IT Costs, each as a share of total administrative costs. Inputs and outputs are averaged over the period 2007 to 2011. 
Table 3: Relative Efficiency - Third Stage Estimates with Full (OECD and Non-OECD) Sample

\begin{tabular}{|c|c|c|c|c|c|c|}
\hline Stage & Total Revenue & PIT & CIT & VAT & PIT, CIT, VAT & PIT and CIT \\
\hline First Stage & 0.828 & 0.830 & 0.819 & 0.839 & 0.859 & 0.839 \\
\hline Third Stage & 0.826 & 0.827 & 0.816 & 0.836 & 0.856 & 0.836 \\
\hline $\mathrm{N}$ & 38 & 38 & 38 & 35 & 35 & 38 \\
\hline & \multicolumn{6}{|c|}{ Efficient Countries } \\
\hline Belgium & 0 & 1 & 0 & 0 & 1 & 1 \\
\hline Bulgaria & 1 & 1 & 1 & 1 & 1 & 1 \\
\hline Cyprus & 1 & 1 & 1 & 1 & 1 & 1 \\
\hline Denmark & 1 & 1 & 0 & 0 & 1 & 1 \\
\hline Iceland & 0 & 0 & 0 & 1 & 1 & 0 \\
\hline Italy & 1 & 1 & 1 & 1 & 1 & 1 \\
\hline Norway & 1 & 0 & 1 & 0 & 1 & 1 \\
\hline South Africa & 1 & 0 & 1 & 1 & 1 & 1 \\
\hline UK & 0 & 0 & 0 & 0 & 1 & 0 \\
\hline
\end{tabular}

Notes: Relatively efficient countries are indicated by the number 1 . The two inputs used in these estimates are 5-year averages of Salary Costs and IT Costs, each as a share of total administrative costs. Inputs and outputs are averaged over the period 2007 to 2011. 
Table 4: Relative Efficiency - Third Stage Estimates using Alternative Input Vector

\begin{tabular}{lcccccc} 
& Total Revenue & PIT & CIT & VAT & PIT, CIT, VAT & PIT and CIT \\
\hline Year & \multicolumn{6}{c}{ OECD Sample } \\
\hline 2011 & 0.561 & 0.551 & 0.365 & 0.424 & 0.732 & 0.658 \\
& 27 & 27 & 27 & 26 & 26 & 27 \\
2009 & 0.476 & 0.599 & 0.308 & 0.354 & 0.723 & 0.674 \\
& 25 & 25 & 25 & 24 & 24 & 25 \\
2007 & 0.521 & 0.603 & 0.293 & 0.400 & 0.767 & 0.678 \\
& 24 & 24 & 24 & 23 & 23 & 24 \\
\hline \multirow{7}{*}{2011} & 0.530 & 0.507 & 0.412 & 0.406 & 0.639 & 0.598 \\
& 34 & 34 & 34 & 32 & 32 & 34 \\
2009 & 0.409 & 0.448 & 0.384 & 0.356 & 0.570 & 0.525 \\
& 33 & 33 & 33 & 31 & 31 & 33 \\
2007 & 0.448 & 0.508 & 0.380 & 0.325 & 0.582 & 0.582 \\
& 29 & 29 & 29 & 27 & 27 & 29 \\
\hline
\end{tabular}

Note: The two inputs used in the estimates are Salary Costs and IT Costs, each relative to the total labor force in the country. Because labor force is only available in 2007, 2009 and 2011, we do not use the five-year averages of labor force when constructing these two variables. Results for each year are provided separately in the table. 
Table 5: Efficient Countries in Any Output Model with Alternative Input Vector (Third Stage)

\begin{tabular}{|c|c|c|c|c|c|c|}
\hline \multirow[b]{2}{*}{ Country } & \multicolumn{3}{|c|}{ OECD Sample } & \multicolumn{3}{|c|}{ Full (OECD and Non-OECD) Sample } \\
\hline & 2007 & 2009 & 2011 & 2007 & 2009 & 2011 \\
\hline Australia & 1 & 1 & 1 & 1 & 1 & 1 \\
\hline Austria & 1 & 1 & . & . & . & . \\
\hline Belgium & . & 1 & . & . & 1 & . \\
\hline Bulgaria & . & . & . & 1 & 1 & 1 \\
\hline Chile & 1 & 1 & 1 & 1 & . & 1 \\
\hline Cyprus & . & . & . & 1 & 1 & 1 \\
\hline Denmark & 1 & . & 1 & 1 & . & 1 \\
\hline Estonia & . & . & 1 & . & . & 1 \\
\hline Hungary & 1 & 1 & 1 & . & . & . \\
\hline Iceland & . & 1 & . & . & 1 & . \\
\hline Italy & 1 & 1 & 1 & 1 & 1 & 1 \\
\hline Korea & 1 & 1 & 1 & . & . & . \\
\hline Malta & . & . & . & 1 & . & 1 \\
\hline Mexico & 1 & 1 & 1 & 1 & 1 & 1 \\
\hline Norway & 1 & 1 & 1 & 1 & 1 & 1 \\
\hline Poland & . & 1 & 1 & . & . & . \\
\hline Portugal & . & . & 1 & . & . & . \\
\hline Slovenia & 1 & . & . & . & . & . \\
\hline South Africa & . & . & . & . & 1 & . \\
\hline Turkey & 1 & 1 & 1 & . & . & . \\
\hline $\mathrm{UK}$ & . & 1 & . & . & 1 & . \\
\hline USA & 1 & . & . & . & . & . \\
\hline
\end{tabular}

Notes: Relatively efficient countries in stage 3 estimates are indicated by the number 1 . A country is marked as efficient if it has a relative efficiency score of 1 in any of the six output specifications in Tables 2 and 3 . The two inputs used in these estimates are Salary Costs and IT Costs, each relative to the total labor force in the country. Because labor force is only available in 2007, 2009 and 2011, we do not use the five-year averages of labor force when constructing these two variables. Results for each year are provided separately in the table. 
Table A1: Relative Efficiency Scores - Third Stage Estimates with OECD Sample

\begin{tabular}{lcccccc}
\hline \multicolumn{1}{c}{ Country } & Total Revenue & PIT & CIT & VAT & PIT, CIT, VAT & PIT and CIT \\
\hline Australia & 0.8566 & 0.8701 & 0.9115 & 0.8566 & 1.0000 & 1.0000 \\
Austria & 0.8371 & 0.7299 & 0.7300 & 0.8148 & 0.8354 & 0.7301 \\
Belgium & 0.7788 & 1.0000 & 0.6650 & 0.7526 & 1.0000 & 1.0000 \\
Canada & 0.7030 & 0.7027 & 0.7028 & 0.7029 & 0.7031 & 0.7029 \\
Chile & 0.7414 & 0.7400 & 1.0000 & 0.8647 & 1.0000 & 1.0000 \\
Czech Republic & 0.7730 & 0.7728 & 0.7889 & 0.8064 & 0.8225 & 0.7890 \\
Denmark & 1.0000 & 1.0000 & 0.7288 & 1.0000 & 1.0000 & 1.0000 \\
Estonia & 0.7085 & 0.7082 & 0.7083 & 0.8275 & 0.8276 & 0.7084 \\
Finland & 0.8401 & 0.8399 & 0.8400 & 0.9332 & 0.9369 & 0.8401 \\
France & 0.8117 & 0.8106 & 0.8111 & 0.8174 & 0.8181 & 0.8114 \\
Germany & 0.6975 & 0.6959 & 0.6967 & 0.6974 & 0.6985 & 0.6971 \\
Hungary & 0.8872 & 0.8708 & 0.8708 & 1.0000 & 1.0000 & 0.8709 \\
Iceland & 0.9544 & 0.9046 & 0.9046 & 1.0000 & 1.0000 & 0.9046 \\
Ireland & 0.7635 & 0.7585 & 0.7586 & 0.7882 & 0.7891 & 0.7587 \\
Italy & 1.0000 & 1.0000 & 1.0000 & 1.0000 & 1.0000 & 1.0000 \\
Japan & 0.6747 & 0.6744 & 0.6745 & 0.6747 & 0.6749 & 0.6746 \\
Korea & 0.8512 & 0.8510 & 0.8622 & 0.8512 & 0.8624 & 0.8623 \\
Luxembourg & 1.0000 & 0.8265 & 0.9388 & 0.8124 & 1.0000 & 1.0000 \\
Mexico & 0.7829 & 0.7817 & 0.7822 & 0.7829 & 0.7837 & 0.7826 \\
Netherlands & 0.8043 & 0.8035 & 0.8036 & 0.8455 & 0.8484 & 0.8037 \\
Norway & 1.0000 & 0.8332 & 1.0000 & 0.8931 & 1.0000 & 1.0000 \\
Poland & 0.9651 & 0.9648 & 0.9649 & 1.0000 & 1.0000 & 0.9650 \\
Portugal & 1.0000 & 1.0000 & 1.0000 & 1.0000 & 1.0000 & 1.0000 \\
Slovenia & 0.8085 & 0.8083 & 0.8084 & 1.0000 & 1.0000 & 0.8085 \\
Spain & 0.8135 & 0.8124 & 0.8129 & 0.8135 & 0.8143 & 0.8132 \\
Turkey & 0.9795 & 0.9794 & 0.9794 & 0.9795 & 0.9796 & 0.9795 \\
UK & 1.0000 & 0.9827 & 0.9548 & 0.9790 & 1.0000 & 0.9905 \\
USA & 0.7615 & 0.7613 & 0.7614 &. & & 0.7614 \\
\hline Not: & & & & \\
& & & & &
\end{tabular}

Note: The two inputs used in these estimates are 5-year averages of Salary Costs and IT Costs, each as a share of total administrative costs. 
Table A2: Relative Efficiency Scores - Third Stage Estimates with Full (OECD and NonOECD) Sample

\begin{tabular}{|c|c|c|c|c|c|c|c|}
\hline OECD? & Country & $\begin{array}{c}\text { Total } \\
\text { Revenue }\end{array}$ & PIT & CIT & VAT & $\begin{array}{c}\text { PIT, CIT, } \\
\text { VAT }\end{array}$ & $\begin{array}{l}\text { PIT and } \\
\text { CIT }\end{array}$ \\
\hline No & Bulgaria & 1.0000 & 1.0000 & 1.0000 & 1.0000 & 1.0000 & 1.0000 \\
\hline No & Cyprus & 1.0000 & 1.0000 & 1.0000 & 1.0000 & 1.0000 & 1.0000 \\
\hline No & India & 0.8716 & 0.8717 & 0.8790 & . & . & 0.8790 \\
\hline No & Latvia & 0.8335 & 0.8337 & 0.8336 & 0.8680 & 0.8680 & 0.8336 \\
\hline No & Lithuania & 0.7204 & 0.7205 & 0.7204 & 0.7864 & 0.7865 & 0.7205 \\
\hline No & Malta & 0.9054 & 0.8837 & 0.8964 & 0.8937 & 0.8967 & 0.8964 \\
\hline No & Romania & 0.7141 & 0.7146 & 0.7143 & 0.7147 & 0.7152 & 0.7144 \\
\hline No & Russia & 0.7758 & 0.7760 & 0.7759 & 0.7760 & 0.7761 & 0.7759 \\
\hline No & S. Africa & 1.0000 & 0.9716 & 1.0000 & 1.0000 & 1.0000 & 1.0000 \\
\hline No & Singapore & 0.9746 & 0.9746 & 0.9842 & . & . & 0.9842 \\
\hline Yes & Australia & 0.8563 & 0.8701 & 0.8787 & 0.8564 & 0.9645 & 0.9644 \\
\hline Yes & Austria & 0.7749 & 0.7298 & 0.7297 & 0.7965 & 0.8231 & 0.7298 \\
\hline Yes & Belgium & 0.6778 & 1.0000 & 0.6646 & 0.6996 & 1.0000 & 1.0000 \\
\hline Yes & Canada & 0.7024 & 0.7026 & 0.7025 & 0.7027 & 0.7028 & 0.7025 \\
\hline Yes & Chile & 0.7028 & 0.7034 & 0.7097 & 0.7434 & 0.7436 & 0.7098 \\
\hline Yes & Czech Republic & 0.7726 & 0.7727 & 0.7792 & 0.8029 & 0.8034 & 0.7792 \\
\hline Yes & Denmark & 1.0000 & 1.0000 & 0.7285 & 0.9048 & 1.0000 & 1.0000 \\
\hline Yes & Estonia & 0.7079 & 0.7081 & 0.7080 & 0.7982 & 0.7983 & 0.7080 \\
\hline Yes & Finland & 0.8398 & 0.8399 & 0.8398 & 0.9284 & 0.9285 & 0.8398 \\
\hline Yes & France & 0.7271 & 0.7276 & 0.7273 & 0.7277 & 0.7281 & 0.7274 \\
\hline Yes & Germany & 0.6749 & 0.6754 & 0.6751 & 0.6755 & 0.6760 & 0.6752 \\
\hline Yes & Hungary & 0.8829 & 0.8707 & 0.8707 & 0.9750 & 0.9824 & 0.8707 \\
\hline Yes & Iceland & 0.9438 & 0.9045 & 0.9045 & 1.0000 & 1.0000 & 0.9045 \\
\hline Yes & Ireland & 0.7620 & 0.7584 & 0.7583 & 0.7842 & 0.7843 & 0.7584 \\
\hline Yes & Italy & 1.0000 & 1.0000 & 1.0000 & 1.0000 & 1.0000 & 1.0000 \\
\hline Yes & Japan & 0.6741 & 0.6743 & 0.6742 & 0.6744 & 0.6745 & 0.6743 \\
\hline Yes & Korea & 0.8509 & 0.8510 & 0.8555 & 0.8510 & 0.8556 & 0.8555 \\
\hline Yes & Luxembourg & 0.7214 & 0.7424 & 0.7215 & 0.7220 & 0.7437 & 0.7418 \\
\hline Yes & Mexico & 0.6977 & 0.6983 & 0.6979 & 0.6984 & 0.6989 & 0.6981 \\
\hline Yes & Netherlands & 0.8038 & 0.8035 & 0.8034 & 0.8453 & 0.8475 & 0.8034 \\
\hline Yes & Norway & 1.0000 & 0.8332 & 1.0000 & 0.8929 & 1.0000 & 1.0000 \\
\hline Yes & Poland & 0.8082 & 0.8086 & 0.8083 & 0.8087 & 0.8090 & 0.8084 \\
\hline Yes & Portugal & 0.7872 & 0.7891 & 0.7874 & 0.7878 & 0.7904 & 0.7885 \\
\hline Yes & Slovenia & 0.8081 & 0.8083 & 0.8082 & 0.9151 & 0.9151 & 0.8082 \\
\hline Yes & Spain & 0.7889 & 0.7893 & 0.7891 & 0.7894 & 0.7898 & 0.7891 \\
\hline Yes & Turkey & 0.8615 & 0.8618 & 0.8616 & 0.8619 & 0.8621 & 0.8617 \\
\hline Yes & UK & 0.9896 & 0.9827 & 0.9532 & 0.9790 & 1.0000 & 0.9883 \\
\hline Yes & USA & 0.7611 & 0.7612 & 0.7611 & . & . & 0.7611 \\
\hline
\end{tabular}

Note: The two inputs used in these estimates are 5-year averages of Salary Costs and IT Costs, each as a share of total administrative costs. 